\title{
Functional Assessment-Based Interventions for Children At-Risk for Emotional and Behavioral Disorders
}

\author{
Alberto F. Restori \\ California State University, Northridge \\ Frank M. Gresham \\ Louisiana State University \\ Tae Chang, \\ Howard B. Lee \& \\ Wilda Laija-Rodriquez \\ California State University, Northridge
}

\begin{abstract}
Functional assessments were conducted to identify the variables maintaining disruptive behavior in eight, typically developing fifth-grade students enrolled in general education classrooms. Participants whose behavior was found to be functionally related to either task-avoidance or attention-seeking were randomly assigned to a treatment strategy that was primarily either antecedent- or consequentbased. An ABAB single-case design was employed to analyze the effects of treatment strategies. The current study also conducted a comparison of treatment strategies that were primarily antecedent- or consequent-based. Results showed that antecedent-based treatment strategies (i.e., self-monitoring and task-modification) were more effective than consequent-based treatment strategies (i.e., differential reinforcement) for increasing academic engagement and reducing disruptive behavior. Implications regarding the use of functional assessment with typically developing students at-risk for emotional and behavioral problems enrolled in general education classrooms and the effects of antecedent- and consequent-based treatment strategies as a function of behavior are discussed.
\end{abstract}

KEYWORDS: Emotional and Behavioral Disorders, Functional Assessment, Behavioral Assessment, Behavioral Interventions, Treatment Strategies.

Students with emotional and behavioral disorders (EBD) are characterized by a number of behavioral, social, and academic characteristics that pose challenges to teachers and administrators. When more global intervention efforts such as primary and secondary prevention programs prove insufficient for shaping behaviors, more ideographic efforts, such as functional assessment-based interventions, are invoked (Horner \& Sugai, 2000; Lane, Robertson, \& Graham-Bailey, 2006).

Functional assessment involves the full range of procedures (e.g., interviews, direct observations, and rating scales) used to identify the antecedent conditions that set the stage for undesirable (target) behaviors to occur and the maintaining consequences (Gresham, Watson, \& Skinner, 2001; Horner, 1994). These data are used to develop a hypothesis statement that can then be tested via experimental manipulation of environmental events. Subsequently, an intervention is designed based on the function of the target behavior.

While the original research on function-based interventions originated in analogue conditions (Iwata, Dorsey, Slifer, Bauman, \& Richmond, 1982), this ideographic approach to intervention has also proved successful in self-contained (Dunlap et al., 1993), inclusive (Kamps, Wendland, \& Culpepper,

Please send correspondence to Alberto Restori, PhD, Assistant Professor, Department of Educational Psychology and Counseling, California State University, Northridge, 18111 Nordhoff Street, Northridge, California 91330. Email: alberto.restori@csun.edu 
2006; Lane, Weisenbach, Little, Phillips, \& Wehby, 2006; Lewis \& Sugai, 1996; Umbreit \& Blair, 1997; Umbreit, Lane, \& Dejud, 2004), and preschool (Umbreit, 1996) settings with a wide range of students, including students with and at risk for EBD (Kern, Delaney, Clarke, Dunlap, \& Childs, 2001; Kern, Hilt, \& Gresham, 2004; Lane, Umbreit, \& Beebe-Frankenberger, 1999; Sasso, Conroy, Stichter, \& Fox, 2001).

Despite these successful demonstrations of functional assessment-based interventions in applied settings, some argue that the literature base is limited by the absence of functional analyses; the lack of a systematic approach to the process; and questionable reliability and validity of some of the tools employed (Sasso et al., 2001). In addition, other concerns focus on the ability to achieve the appropriate balance between scientific rigor and feasibility when conducting research in applied settings (Scott et al., 2004) and the goal of focusing more primarily on antecedent-based, rather than consequent-based interventions (Restori et al., in review).

Historically, many teachers and researchers have relied heavily on consequent-based interventions in which the target behavior must occur and subsequently be shaped by the consequences that follow (Lewis \& Sugai, 1996; Martens, Peterson, Witt, \& Cirone, 1986). That is, consequences, often in the form of punitive responses, are applied after the occurrence of an academic or behavioral problem. Research by Newcomer and Lewis (2004) indicates that such a consequent-based approach is not likely to offer the best approach for remediation of academic and behavioral challenges.

One review of the research on behavior disorders indicated that only $11.1 \%$ of the individuals treated for maladaptive behavior received treatments that were based primarily upon the manipulation of antecedent variables (Lennox, Miltenberger, Spengler, \& Erfanian 1988). More recently, increased attention has been placed on the value of antecedent-based interventions in which environmental and curricular modifications are made to prevent the problem behavior from occurring (Clarke et al., 1995; Dunlap, White, Vera, Wilson, \& Panacek, 1996; Kern et al., 2001; Kern \& Clemens, 2007). While most function-based interventions contain both components (antecedent adjustments and modification of the reinforcement schedules), one could argue that an intervention could be either primarily antecedent-based or primarily consequent-based. Given the increased emphasis on prevention, one question arises as to the extent to which interventions that are primarily antecedent- or consequent-based are equally effective in producing meaningful, lasting change.

To this end, Restori and colleagues (in review) conducted as series of function-based interventions, some primarily antecedent-based and others primarily consequent-based, with eight second grade students with disruptive behavior patterns. Functional assessments were conducted to identify the maintaining variables, which yielded those maintained by task-avoidance or attention-seeking. Results of a series of $A B A B$ withdrawal designs suggested that antecedent-based treatment strategies (i.e., self-monitoring and task-modification) were as effective and efficient as consequent-based treatment strategies (i.e., differential reinforcement) for increasing academic engagement and reducing disruptive behavior for these general education students. However, questions arise as to the consistency of these findings with older students, who may be less amenable to intervention efforts (Walker, Ramsey, \& Gresham, 2004). That is, previous research has demonstrated that disruptive patterns of behavior become more stable as children grow older and are likely to be more resistant to change (e.g., Olweus, 1979; Walker et al., 2004). Therefore, the authors of the current study investigated whether antecedent-based and consequent-based interventions were equally effective for upper elementary students with disruptive behaviors. 


\section{Purpose}

This study seeks to extend the Restori and colleagues (in review) investigation by examining the efficacy of function-based interventions that were either primarily antecedent-based or primarily consequent-based with fifth-grade students whose patterns of disruptive behavior were similar to that of their second grade sample. We hypothesize that results will be comparable to those in the study of second grade students, but that the magnitude of improvement may be less given that behavior patterns become more resistant to intervention efforts over time (Walker et al., 2004).

\section{METHOD}

\section{Participants and Setting}

Eight fifth-grade, general education students from two elementary schools in southern California were selected to participate in the study. Written consent to conduct the study was granted by the Director of Special Education of the school district, school principals, and the fifth grade teachers of the two schools included in the study. Parents of the participants gave written permission for their child to be included in the study and had the option to withdraw their child from the study at any time. All of the participants gave their verbal consent to be included in the study and were given the option to withdraw from the study with their parent's permission. The district serves an urban, ethnically diverse population with socioeconomic status ranging from lower to upper-middle class. Four of the participants were African American, two Latino, and two Anglo. All eight participants were male and five of the eight participants were enrolled in general education classes for their entire school day. Three of the participants received special education support (i.e., resource specialist program [RSP]) for an hour per day (i.e., homework club). None of the participants had a neurological, psychiatric, or physical disability that could prevent him from behaving appropriately (e.g., autism) or that would interfere with academic performance (e.g., mental retardation). None of the participants in the study was classified as Emotionally Disturbed (ED), nor enrolled in a Special Day Class (SDC). Information regarding special education support, disabilities, and/or placement was obtained from parent and teacher interviews, school records, and student observations.

\section{Procedures}

Fifth grade teachers from the two elementary schools were asked to nominate his or her three to five most disruptive students. Students nominated for the study had varying degrees of suspensions, referrals to the school principal or counselor, and out-of-class suspensions (OCS), however, school personnel agreed that all of the students nominated for inclusion to the study demonstrated significant behavioral problems and were considered at-risk for emotional and behavioral disorders. A functional assessment consisting of direct student observations employing an A-B-C approach, (i.e., descriptive assessment), interview with the classroom teacher, and completion of the Social Skills Rating System-Teacher form (SSRS-T; Gresham \& Elliott, 1990) was conducted with each participant to determine the degree of disruptive, off-task, and on-task behaviors. Preliminary classroom observations were 15 minutes in duration and used for gathering baseline data of the referred students as well as to identify other potential participants for the study. Only students whose disruptive behavior was clearly identified as having a functional relationship to either task-avoidance or attention-seeking were included in the study. Students whose behavior served a dual function (i.e., task-avoidance and attention-seeking), was undifferentiated (i.e., not clearly task-avoidance or attention-seeking), or whose behavior was functionally related 
to sensory reinforcement were excluded from the study. Although some students may have multiple or undifferentiated functions of behavior, previously cited research has demonstrated that a comprehensive functional assessment is likely to result in an accurate hypothesis statement regarding a child's primary function of behavior within a given setting. After completion of the identification process, the eight participants were randomly assigned to receive a treatment strategy that was either primarily antecedentor consequent-based and matched to their individual function of behavior.

Students selected to participate in the study met the following criteria. First, participants must exhibit disruptive behavior for a minimum of $25 \%$ of the intervals observed during four or more of the baseline observations. Second, students must be academically engaged during less than $25 \%$ of the intervals observed during four or more of the baseline observations. Classroom observations and teacher reports indicate that the majority of students engaged in disruptive behavior less than $10 \%$ of the time and were academically engaged or engaged in task-related activities at least $90 \%$ of the time. Third, the overall Social Skills and Academic Competence scores of the SSRS-T was below the 25th percentile and the overall Problem Behaviors score of the SSRS-T was above the 75th percentile. Finally, as previously stated, the function of behavior (i.e., task-avoidance or attention-seeking) must be clearly identified.

Participants' data were coded and reported by letter and number to maintain their anonymity. The letter referred to the treatment strategy the participant received. Participants receiving an antecedentbased treatment strategy were coded with the letter A and participants receiving a consequent-based treatment strategy were coded with the letter C. Participants 1 and 2 for both the A and C groups designate the participants whose function of behavior was attention-seeking. Likewise, participants 3 and 4 for both the $\mathrm{A}$ and $\mathrm{C}$ groups designate the participants whose function of behavior was task-avoidance. For example, participant A1 was a participant assigned to an antecedent-based treatment strategy whose disruptive behavior was functionally related to attention-seeking.

\section{Measures}

Disruptive behavior. Disruptive behavior was defined employing a modified version of the seven general categories of behavior incompatible with learning described by Becker, Madsen, Arnold, and Thomas (1967). The following four general categories were used to define disruptive behavior for the current study: (a) unauthorized out-of-seat behaviors, (b) disruptive noise, (c) disturbing others, and (d) talking without teacher permission. Out-of-seat behaviors include any unauthorized or non-task related movement within the classroom. Disruptive noise included excessive flipping of pages, pencil tapping, or any non-task related noise (e.g., humming). Disturbing others included physical contact with another student, their desk, any objects on another student's desk; and aggressive behavior (e.g., hitting another student). Talking without teacher permission included responding to a teacher's question without being called upon to reply, talking to another student while the teacher is giving a lesson, or talking during a written assignment.

Academic engagement. The current study adopted the definition of Academic Engaged Time (AET) from Walker and Severson's (1991) Systematic Screening for Behavior Disorders (SSBD). Academic engagement was defined as a student properly working on assigned academic material. An academically engaged student is (a) attending to the material and task, (b) making appropriate motor and/or verbal responses (e.g., writing, computing, answering questions), and (c) asking for assistance (when appropriate) in an acceptable manner. For example, a student listening to a teacher's lesson or computing assigned math problems is considered to be academically engaged. A student not actively working on a class assignment, not attending to the teacher's lesson, and/or breaking classroom rules are examples of 
not exhibiting academically engaged behavior.

\section{Technical Instrumentation}

Social Skills Rating System - Teacher (SSRS-T; Gresham \& Elliott, 1990). The SSRS-T provides a broad assessment of a student's social behaviors that can affect teacher-student relations, peer acceptance, and academic performance. The SSRS-T was standardized on a representative sample of students 3-18 years. The SSRS-T documents the perceived frequency and importance of behaviors influencing students' development of social competence and adaptive functioning at school. The teacher version contains ratings of three social skill domains (Cooperation, Assertion, and Self-Control) and three problem behavior domains (Internalizing Problems, Externalizing Problems, and Hyperactivity Problems). The SSRS-T also contains a teacher rating of academic competence. Extensive evidence of reliability, as well as content, social and criterion-related validity is provided in the SSRS manual.

\section{Observation and Recording Procedures}

Students selected as participants for the study exhibited high rates of disruptive behavior and low rates of academic engagement as a function of either task-avoidance or attention-seeking. Observations for all participants in all phases of the study were conducted during reading or reading related lessons based on information gathered from teacher interviews. Although teachers reported that the participants demonstrated disruptive behavior throughout the day, they reported that such behaviors appeared to be more frequent during language arts instruction. Participants were observed in 10-second intervals for 15 minutes. A partial-interval, time-sampling procedure was used for recording off-task and disruptive behavior and a whole-interval, time-sampling procedure for recording academic engagement. At the end of each 10-second interval, the participant's behavior was recorded indicating academic engagement (AE), off-task (OFF), or disruptive behavior (DIS). When a participant exhibited any off-task or disruptive behavior during a given interval, DIS or OFF was recorded on the observation form. If a participant displayed both disruptive and off-task behaviors within a given interval, DIS was recorded on the observation form. Participants had to remain academically engaged throughout the entire 10 -second interval to be considered academically engaged (AE). The percentages of disruptive behavior, off-task behavior, and academic engagement were calculated for each student after each 15-minute observation. Although there was some risk of over-estimating disruptive behavior and underestimating academic engagement using this observation system, this approach would likely produce more meaningful information when comparing treatment outcomes to baseline levels of each behavior. To calculate the percentage of intervals in which disruptive behavior, off-task behavior, or academic engagement occurred, the number of intervals in which each occurred was divided by the total number of intervals and multiplied by 100 . Each 15-minute observation session was considered one data point and a minimum of four data points was required to establish a stable rate of responding in both baseline and treatment phases.

Inter-observer agreement of direct observations was conducted by the first author and a research assistant (RA) by observing the target student at the same time from different places in the classroom employing the previously described observation and recording procedures. A minimum of $20 \%$ of all observation sessions included inter-rater reliability probes to ensure adequate levels of reliability. Interrater reliability probes were conducted across all phases of the study. The percentage of inter-observer agreement for all reliability probes was $80 \%$ or above. 
TABLE 1. Description of Antecedent-Based Treatment Strategies for Fifth Grade Participants

\begin{tabular}{|c|c|c|c|}
\hline Student & Assignment & Hypothesis & Modifications \\
\hline A1 & $\begin{array}{l}\text { Students were } \\
\text { expected to read } \\
\text { silently. Questions } \\
\text { pertaining to reading } \\
\text { assignment were } \\
\text { asked after specified } \\
\text { period of time. } \\
\text { Classroom points } \\
\text { were contingent on } \\
\text { all students' } \\
\text { participation. }\end{array}$ & $\begin{array}{l}\text { Attention- } \\
\text { Seeking }\end{array}$ & $\begin{array}{l}\text { Self-Monitoring } \\
\text { 1. Explain self-monitoring } \\
\text { procedure to A1. } \\
\text { 2. Provide self-monitoring form. } \\
\text { 3. Provide } 5 \text { verbal/physical } \\
\text { prompts. } \\
\text { 4. Student and teacher monitor } \\
\text { on-task behavior. } \\
\text { 5. Compare self-monitoring forms } \\
\text { 6. Provide verbal praise for } \\
\text { accurate self-monitoring. } \\
\text { 7. Provide preferred activity for } \\
\text { accurate self-monitoring and on- } \\
\text { task-behavior. }\end{array}$ \\
\hline A2 & $\begin{array}{l}\text { Students were } \\
\text { expected to read } \\
\text { silently or complete } \\
\text { unfinished work } \\
\text { during this time. } \\
\text { Students were } \\
\text { expected to read or } \\
\text { work silently without } \\
\text { disturbing other } \\
\text { students. }\end{array}$ & $\begin{array}{l}\text { Attention- } \\
\text { Seeking }\end{array}$ & $\begin{array}{l}\text { Self-Monitoring } \\
\text { 1. Explain self-monitoring } \\
\text { procedure toA2. } \\
\text { 2. Provide self-monitoring form. } \\
\text { 3. Provide } 5 \text { verbal/physical } \\
\text { prompts. } \\
\text { 4. Student and teacher monitor } \\
\text { on-task behavior. } \\
\text { 5. Compare self-monitoring forms. } \\
\text { 6. Provide verbal praise for } \\
\text { accurate self-monitoring. } \\
\text { 7. Provide preferred activity for } \\
\text { accurate self-monitoring and on- } \\
\text { task-behavior. }\end{array}$ \\
\hline
\end{tabular}




\begin{tabular}{|c|c|c|c|}
\hline A3 & $\begin{array}{l}\text { Students were } \\
\text { expected to read } \\
\text { silently. Questions } \\
\text { pertaining to reading } \\
\text { assignment were } \\
\text { asked after } \\
\text { specified period of } \\
\text { time. Classroom } \\
\text { points were } \\
\text { contingent on all } \\
\text { students } \\
\text { participation. }\end{array}$ & $\begin{array}{l}\text { Task } \\
\text { Avoidance }\end{array}$ & $\begin{array}{l}\text { Task-Modification } \\
\text { 1. Tell A3 to read grade level book } \\
\text { for } 10 \text { minutes before he can read } \\
\text { preferred book. } \\
\text { 2. Allow A3 to select a book/story } \\
\text { he likes. } \\
\text { 3. Pair A3 with a classmate to read } \\
\text { with. } \\
\text { 4. After } 10 \text { minutes, ask A3 } \\
\text { questions about story. } \\
\text { 5. Provide verbal praise for } \\
\text { answering questions and provide } \\
\text { time to read preferred story. }\end{array}$ \\
\hline A4 & $\begin{array}{l}\text { Students were } \\
\text { expected to read } \\
\text { silently from } \\
\text { pre-assigned } \\
\text { material. Students } \\
\text { were expected to } \\
\text { complete } \\
\text { associated } \\
\text { worksheets and not } \\
\text { disturb other students. }\end{array}$ & $\begin{array}{l}\text { Task } \\
\text { Avoidance }\end{array}$ & $\begin{array}{l}\text { Task-Modification } \\
\text { 1. Tell A4 to read grade level book } \\
\text { for } 10 \text { minutes before he can read } \\
\text { preferred book. } \\
\text { 2. Allow A4 to select a book/story } \\
\text { he likes. } \\
\text { 3. Pair A4 with a classmate to read } \\
\text { with. } \\
\text { 4. After } 10 \text { minutes, ask A4 } \\
\text { questions about story. } \\
\text { 5. Provide verbal praise for } \\
\text { answering questions and provide } \\
\text { time to read preferred story }\end{array}$ \\
\hline
\end{tabular}


TABLE 2. Description of Consequent-Based Treatment Strategies for Fifth Grade Participants.

\begin{tabular}{|c|c|c|c|}
\hline Student & Assignment & Hypothesis & Modifications \\
\hline $\mathrm{C} 1$ & $\begin{array}{l}\text { Students were expected } \\
\text { to read silently from } \\
\text { pre-assigned material. } \\
\text { Students were expected } \\
\text { to complete associated } \\
\text { worksheets and not disturb } \\
\text { other students. }\end{array}$ & $\begin{array}{l}\text { Attention- } \\
\text { Seeking }\end{array}$ & $\begin{array}{l}\text { DRO with preferred activity } \\
\text { 1. Assign C5 a book to read. } \\
\text { 2. Provide immediate verbal praise } \\
\text { for academic engagement in the } \\
\text { absence of disruptive behavior } 5 \\
\text { times within } 15 \text { minute } \\
\text { observation period. } \\
\text { 3. Provide free-time for to draw for } \\
\text { appropriate behavior. }\end{array}$ \\
\hline $\mathrm{C} 2$ & $\begin{array}{l}\text { Students were expected to } \\
\text { read silently or complete } \\
\text { unfinished work during } \\
\text { this time. Students were } \\
\text { expected to read or work } \\
\text { silently without disturbing } \\
\text { other students. }\end{array}$ & $\begin{array}{l}\text { Attention- } \\
\text { Seeking }\end{array}$ & $\begin{array}{l}\text { DRO } \\
\text { 1. Provide reading assignment. } \\
\text { 2. Provide immediate verbal praise } \\
\text { for academic engagement in the } \\
\text { absence of disruptive behavior } 5 \\
\text { times within } 15 \text { minute } \\
\text { observation period. }\end{array}$ \\
\hline C3 & $\begin{array}{l}\text { Students were expected } \\
\text { to complete math work- } \\
\text { sheets, which included } \\
\text { word problems. Students } \\
\text { were expected to work } \\
\text { silently without disturbing } \\
\text { other students. }\end{array}$ & $\begin{array}{l}\text { Task } \\
\text { Avoidance }\end{array}$ & $\begin{array}{l}\text { DRO } \\
\text { 1. Provide math worksheet. } \\
\text { 2. Provide immediate verbal praise } \\
\text { for academic engagement in the } \\
\text { absence of disruptive behavior } 5 \\
\text { times within } 15 \text { minute } \\
\text { observation period. }\end{array}$ \\
\hline $\mathrm{C} 4$ & $\begin{array}{l}\text { Students were expected } \\
\text { to read silently from } \\
\text { pre-assigned material. } \\
\text { Students were expected } \\
\text { to complete associated } \\
\text { worksheets and not disturb } \\
\text { other students. Two tables } \\
\text { were selected each day to } \\
\text { read in small groups for } \\
\text { the teacher. }\end{array}$ & $\begin{array}{l}\text { Task } \\
\text { Avoidance }\end{array}$ & $\begin{array}{l}\text { DRO } \\
\text { 1. Assign reading or spelling lesson. } \\
\text { 2. Provide immediate verbal praise } \\
\text { for academic engagement in the } \\
\text { absence of disruptive behavior } 5 \\
\text { times within } 15 \text { minute } \\
\text { observation period. }\end{array}$ \\
\hline
\end{tabular}




\section{Interventions}

Participants for the current study were assigned to a treatment strategy that was either primarily antecedent- or consequent-based and matched to their function of behavior. Antecedent-based treatment strategies consisted of self-monitoring for the two participants whose disruptive behavior was functionally related to attention-seeking and task-modification for the two participants whose disruptive behavior was functionally related to task-avoidance. Consequent-based treatment strategies consisted of differential reinforcement of other behaviors (DRO) for three of the participants and DRO with preferred activity for one participant (see Tables 1 and 2 for descriptions of each participant's treatment plans). Although each participant received his own individual treatment plan, the following is a general overview of the interventions used, by whom and how they were implemented, and other pertinent information related to the intervention strategies used.

Self-monitoring. The current study modified the self-monitoring procedures described by Shapiro and Cole (1992) to fit the general education classroom and curriculum. In the current study, the teacher was trained by the primary investigator to implement the self-monitoring procedure. The classroom teacher was required to tap on the student's shoulder when it was time to self-monitor their behavior. Selfmonitoring was done on a variable-interval 3-minute schedule (VI-3m). At that time, both the teacher and student monitored the student's behavior. During natural breaks in the school day (e.g., recess and lunch-time), the teacher and student reviewed the student's self-monitoring forms. Reinforcement in the form of verbal praise and access to preferred activities were dispensed for accurate self-monitoring and on-task behavior.

Task-modification. The current study modified the task-modification procedure described by Dunlap and Kerns (1996) to fit the general education classroom and curriculum. In the current study, the teacher was trained by the primary investigator to implement the task-modification procedure. Participants receiving a task-modification intervention strategy were to select two books to read. One book would be a preferred book, the other, a grade-level book. The participant was to read the grade-level book with a preferred, competent reading peer for 10 minutes. Once the passage was read, the teacher asked questions pertaining to the reading to assess comprehension. After reading the grade-level book, the participant was permitted to read his preferred book and provided with verbal praise.

Differential reinforcement. Differential reinforcement typically involves withholding reinforcement of an undesirable behavior (extinction) and delivering reinforcement contingent on other appropriate behavior (Marcus \& Vollmer, 1996). Teachers were trained by the primary investigator to deliver a modified differential reinforcement of other behaviors (DRO). DRO is the delivery of reinforcement immediately following the performance of a desired behavior in the absence of the target behavior (Cooper, Herron, \& Heward, 2007). Participants were provided with verbal praise for academic engagement in the absence of disruptive behavior.

\section{Experimental Design and Data Analysis}

Intervention outcomes were analyzed using a within-series, ABAB reversal design. In this design, each participant serves as his own control, thereby, minimizing the idiosyncratic interactions that have the potential for confounding the interpretations and results when comparing one subject with another. In the current study, baseline and reversal to baseline phase data were collected until a stable trend, with a minimum of four data points per phase was established. In both of these phases, the classroom teacher delivered instruction using his or her own behavior management system without any additional interventions for the participants of the current study. Similarly, during both treatment phases, data were collected 
for a minimum of four data points for each treatment phase to determine the effects of the intervention strategies. Two follow-up phases at 15 and 30 days were also conducted to evaluate the maintenance of increased academic engagement and reduced disruptive behavior as a function of treatment. During the follow-up phases, teachers were not required to implement the student's previously developed individual treatment plans. Graphed data were analyzed using traditional visual inspection (Johnston \& Pennypacker, 1993) and mean score comparison techniques to determine the effects of treatment strategies.

\section{Treatment Integrity}

Treatment integrity is defined as the degree to which a treatment plan is implemented as intended (Gresham, 1989). Unless an intervention is carried out exactly as planned, results regarding change in the target behavior cannot be attributed to the intervention. Fuchs and Fuchs (1989) recommend the use of a component analysis checklist, wherein, a list of the components of an intervention strategy is provided to the teacher. In the current study, the teacher and researcher checked off each component of the intervention strategy as they were implemented during each observation. The component analysis checklist was reviewed by the primary investigator to determine if a particular component of the intervention strategy was consistently ignored. Although the percentage of treatment integrity for a given treatment strategy was not calculated, a visual inspection of the component analysis checklists completed by both the teacher and researcher indicate that the components of each intervention strategy were implemented with high integrity.

\section{RESULTS}

Figures 1 and 2 display the percentage of intervals of academic engagement and disruptive behavior for each participant across baseline, treatment, and follow-up phases. Overall, both antecedent- and consequent-based treatment strategies were effective, regardless of function of behavior. Table 3 provides the means and standard deviations for both academic engagement and disruptive behavior during each phase of the study. Results of the SSRS-T pre and post measures indicate relatively small and inconsistent changes on its various scales regardless of treatment strategy or function of behavior (see Table 4). Although results of the SSRS-T pre and post measures were relatively small and inconsistent, teachers reported they observed positive changes in the social skills domains assessed by the SSRS-T in all of their students included in the study. Furthermore, the data from both Figures and Table 3 provide clear evidence of meaningful and substantial change in behavior resulting from both antecedent- and consequent-based treatment strategies.

\section{Academic engagement}

Most participants displayed stable patterns of low academic engagement during the initial baseline sessions. Although all participants met the pre-established criteria of academic engagement for inclusion into the study, when compared to each other they exhibited considerable variability in academic engagement during the initial baseline phase of the study. Overall, participants were academically engaged an average of $22.4 \%(S D=16.9)$ of the intervals during the initial baseline phase. A low pattern of academic engagement was not as distinct during the reversal to baseline phase as it was during the initial baseline phase. During the reversal to baseline phase, overall average academic engagement was observed during $37.4 \%(S D=22.9)$ of the intervals.

All participants showed a significant increase in academic engagement during both treatment phases. 
Figure 1. Percentage of intervals for academic engagement and disruptive behavior during baseline, treatment, and follow-up phases.
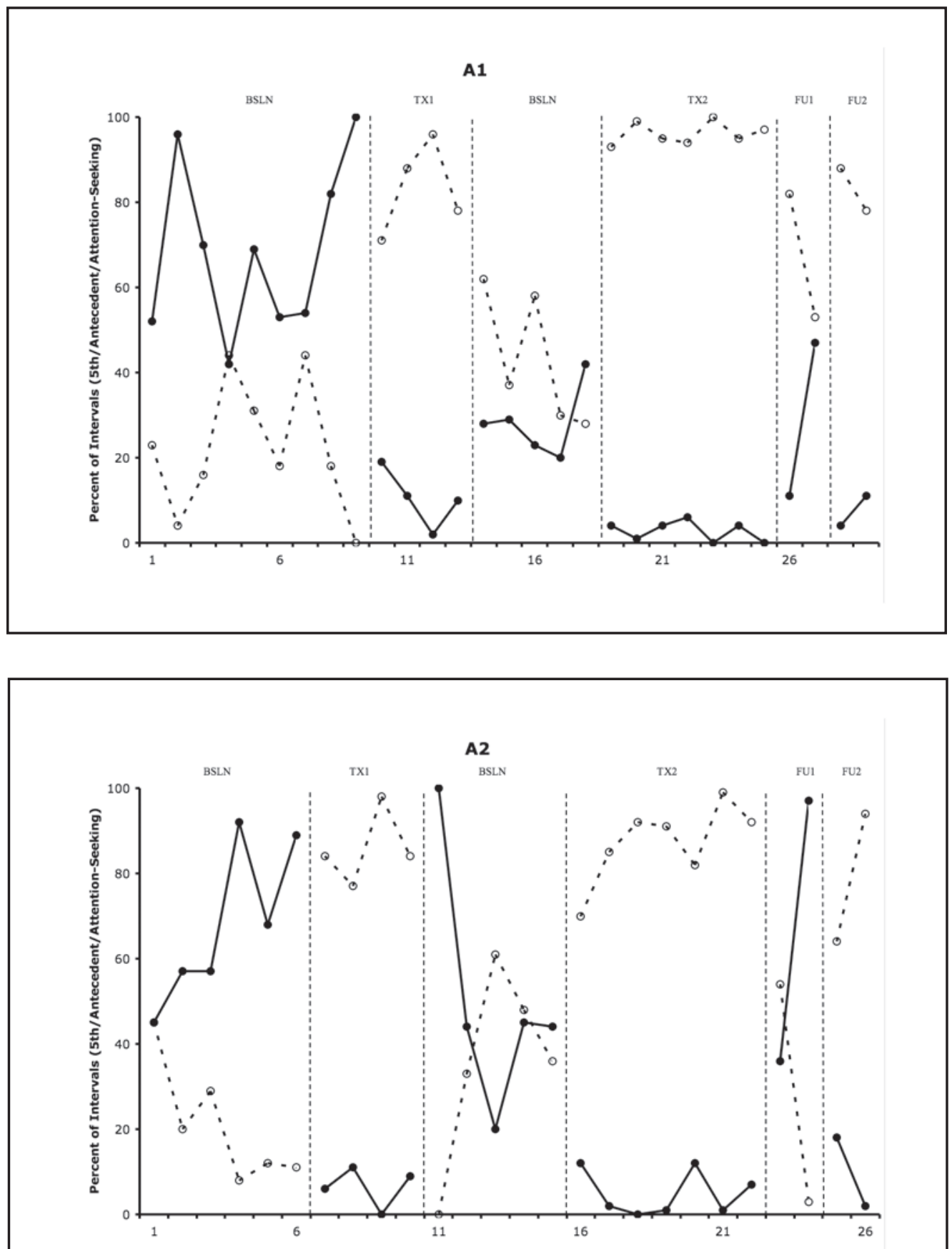

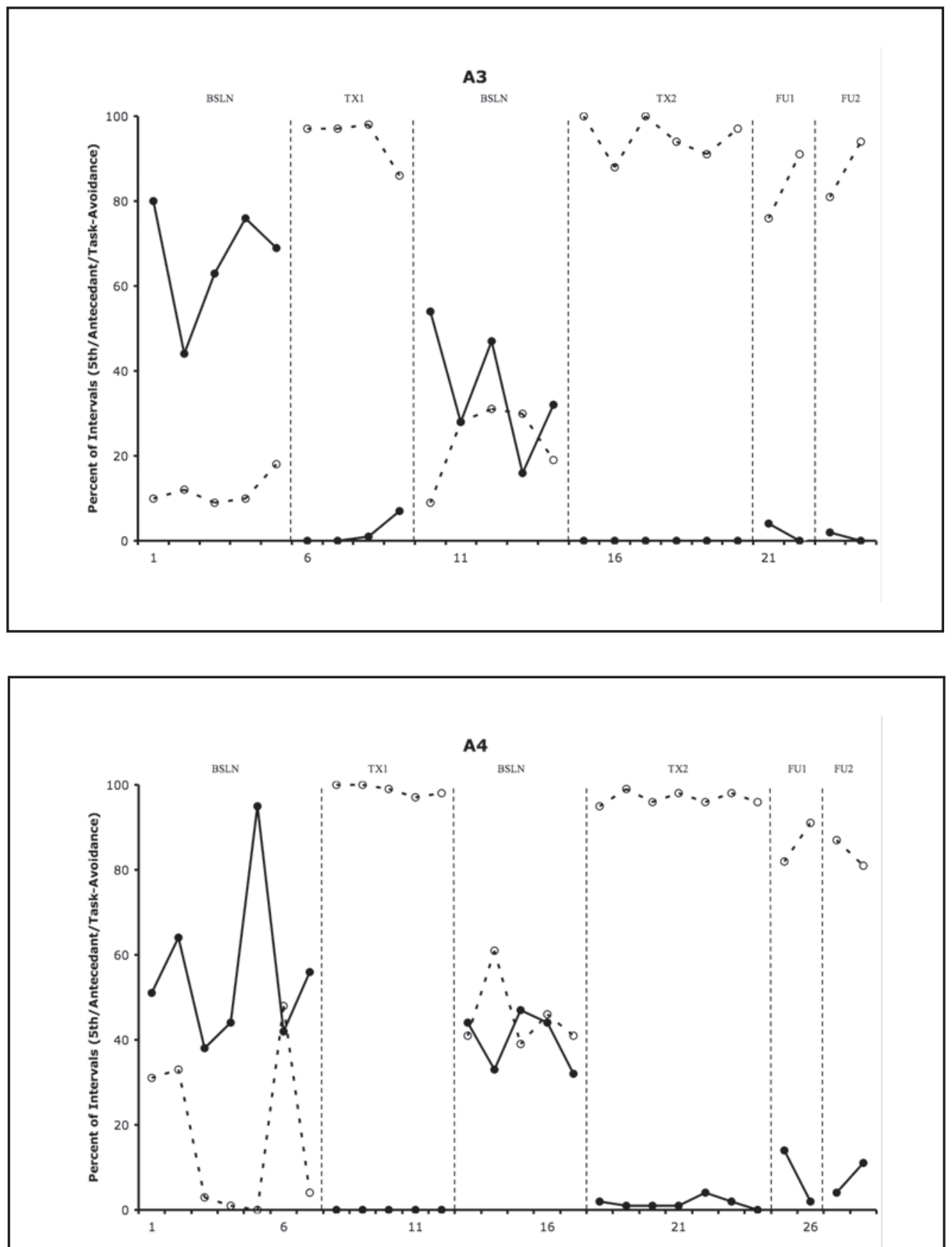
Figure 2. Percentage of intervals for academic engagement and disruptive behavior during baseline, treatment, and follow-up phases..
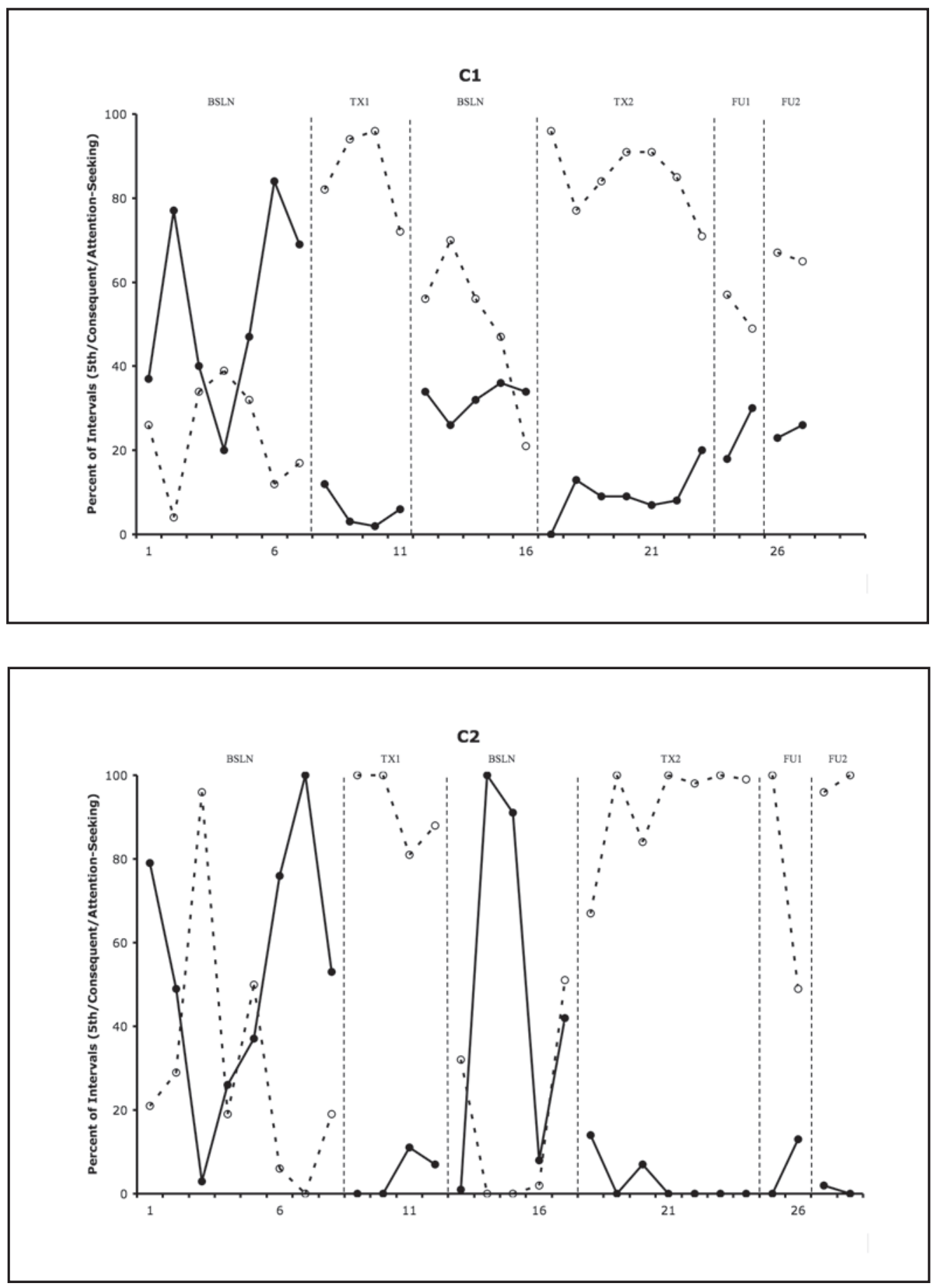

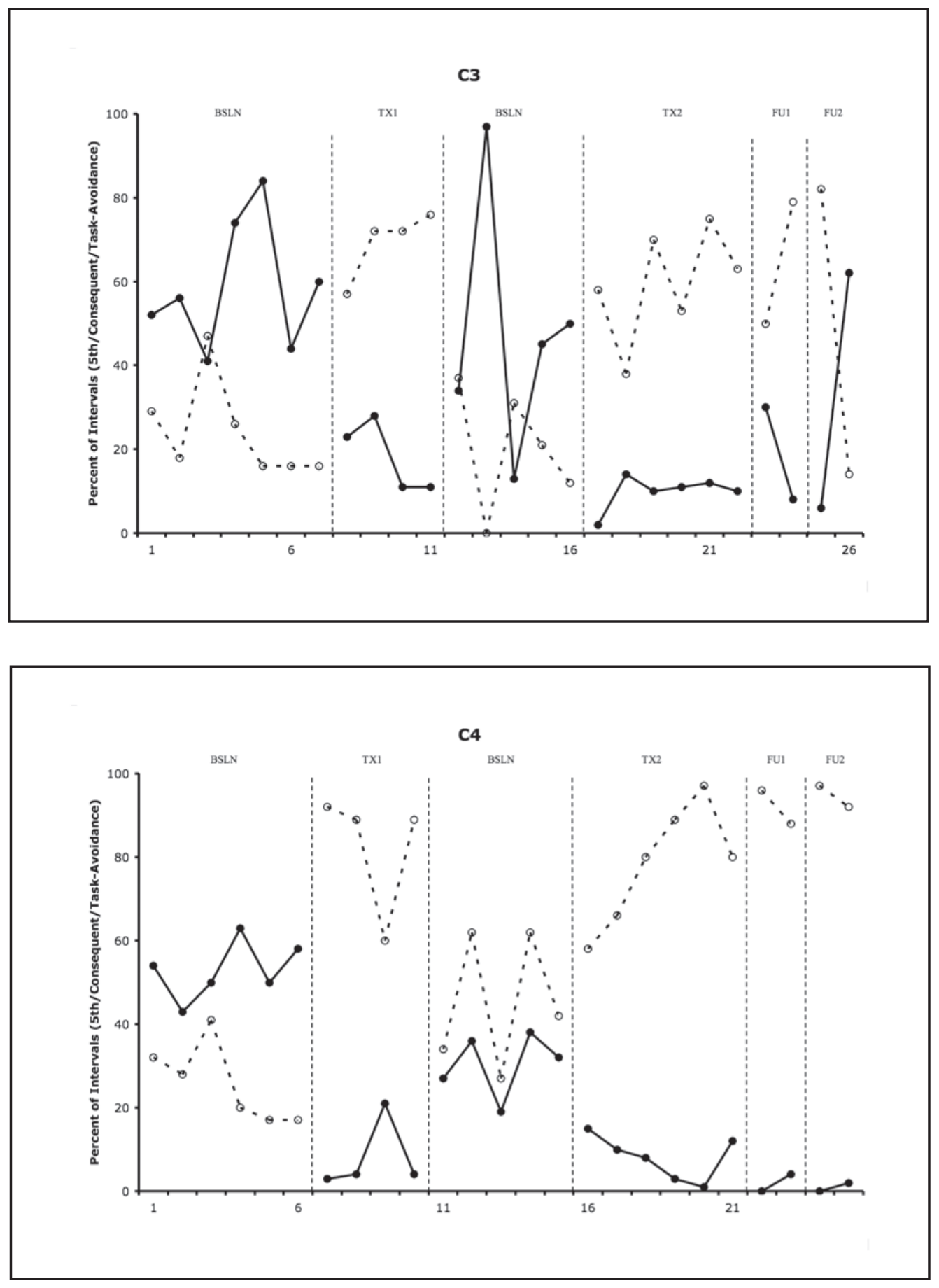
TABLE 3. Means and Standard Deviations for Academic Engagement and Disruptive Behavior of Eight $5^{\text {th }}$-Grade Students

\begin{tabular}{|c|c|c|c|c|}
\hline \multirow[b]{2}{*}{ Overall } & \multicolumn{2}{|c|}{ Academic Engagement } & \multicolumn{2}{|c|}{ Disruptive Behavior } \\
\hline & M & SD & M & SD \\
\hline Baseline & 22.35 & 16.89 & 59.53 & 20.44 \\
\hline Treatment 1 & 86.90 & 12.26 & 6.77 & 7.63 \\
\hline Baseline & 37.41 & 22.86 & 38.31 & 23.90 \\
\hline Treatment 2 & 83.08 & 18.57 & 6.49 & 8.04 \\
\hline Follow Up 1 & 75.29 & 25.04 & 15.62 & 22.99 \\
\hline Follow Up 2 & 80.00 & 20.99 & 10.81 & 15.98 \\
\hline Attn. Seek / Antecedent & M & SD & M & SD \\
\hline Baseline & 21.53 & 14.45 & 68.40 & 19.18 \\
\hline Treatment 1 & 83.67 & 9.27 & 9.33 & 6.28 \\
\hline Baseline & 50.11 & 28.11 & 35.78 & 28.52 \\
\hline Treatment 2 & 76.58 & 25.18 & 10.42 & 12.62 \\
\hline Follow Up 1 & 74.78 & 32.46 & 22.78 & 32.47 \\
\hline Follow Up 2 & 81.00 & 13.11 & 8.75 & 7.27 \\
\hline Attn. Seek / Consequent & M & SD & M & SD \\
\hline Baseline & 26.93 & 23.45 & 53.13 & 27.07 \\
\hline Treatment 1 & 89.13 & 10.13 & 5.13 & 4.67 \\
\hline Baseline & 33.50 & 26.31 & 40.40 & 31.79 \\
\hline Treatment 2 & 88.79 & 11.16 & 6.21 & 6.49 \\
\hline Follow Up 1 & 63.75 & 24.46 & 15.25 & 12.42 \\
\hline Follow Up 2 & 82.00 & 18.57 & 12.75 & 13.65 \\
\hline Task Avoid / Antecedent & M & $\mathrm{SD}$ & M & $\mathrm{SD}$ \\
\hline Baseline & 14.92 & 14.95 & 60.17 & 17.59 \\
\hline Treatment 1 & 96.89 & 4.26 & 0.89 & 2.32 \\
\hline Baseline & 34.50 & 14.55 & 37.70 & 11.40 \\
\hline Treatment 2 & 96.00 & 3.46 & 0.85 & 1.21 \\
\hline Follow Up 1 & 85.00 & 7.35 & 5.00 & 6.22 \\
\hline Follow Up 2 & 85.75 & 6.18 & 4.25 & 4.79 \\
\hline Task Avoid / Consequent & M & SD & M & SD \\
\hline Baseline & 24.85 & 10.25 & 56.08 & 12.27 \\
\hline Treatment 1 & 75.88 & 13.32 & 13.13 & 9.70 \\
\hline Baseline & 32.80 & 19.70 & 39.10 & 23.16 \\
\hline Treatment 2 & 68.92 & 16.42 & 9.00 & 4.63 \\
\hline Follow Up 1 & 78.25 & 20.07 & 10.50 & 13.40 \\
\hline Follow Up 2 & 71.25 & 38.67 & 17.50 & 29.77 \\
\hline
\end{tabular}


TABLE 4. SSRS pre-test and post-test results. Standard scores and percentiles for Social Skills, Problem Behaviors, and Academic Competence.

\begin{tabular}{|c|c|c|c|c|c|c|}
\hline \multirow[t]{2}{*}{ Student } & \multicolumn{2}{|c|}{ Social Skills } & \multicolumn{2}{|c|}{ Problem Behaviors } & \multicolumn{2}{|c|}{ Academic Competence } \\
\hline & Pre-test & Post-test & Pre-test & Post-test & Pre-test & Post-test \\
\hline A1 & $85(16 \%)$ & $91(27 \%)$ & $118(88 \%)$ & $123(94 \%)$ & $82(12 \%)$ & $91(27 \%)$ \\
\hline $\mathrm{A} 2$ & $73(4 \%)$ & $78(7 \%)$ & $127(96 \%)$ & $125(95 \%)$ & $78(7 \%)$ & $83(13 \%)$ \\
\hline A3 & $70(2 \%)$ & $95(37 \%)$ & $127(96 \%)$ & $95(37 \%)$ & $85(16 \%)$ & $83(13 \%)$ \\
\hline A4 & $81(10 \%)$ & $90(25 \%)$ & $125(95 \%)$ & $112(79 \%)$ & $74(4 \%)$ & $83(13 \%)$ \\
\hline $\mathrm{C} 1$ & $82(12 \%)$ & $82(12 \%)$ & $112(79 \%)$ & $110(75 \%)$ & $112(79 \%)$ & $110(75 \%)$ \\
\hline $\mathrm{C} 2$ & $86(18 \%)$ & $92(30 \%)$ & $136(>98 \%)$ & $135(>98 \%)$ & $74(4 \%)$ & $82(12 \%)$ \\
\hline $\mathrm{C} 3$ & $46(<2 \%)$ & $90(25 \%)$ & $108(70 \%)$ & $95(37 \%)$ & $79(8 \%)$ & $78(7 \%)$ \\
\hline $\mathrm{C} 4$ & $76(5 \%)$ & $8618 \%$ & $120(91 \%)$ & $115(84 \%)$ & $76(5 \%)$ & $76(5 \%)$ \\
\hline
\end{tabular}

Overall, academic engagement increased to an average of $86.9 \%(S D=12.3)$ of the intervals during Treatment phase 1. All participants also displayed a significant increase in academic engagement when treatment strategies were re-introduced after the reversal to baseline phase was concluded. The overall mean of academic engagement increased to $83.1 \%(S D=18.6)$ of the intervals during Treatment phase 2 . Results regarding the overall maintenance of treatment effects indicate that increased levels of academic engagement were sustained over 15- and 30-day periods. Overall academic engagement was observed an average of $75.3 \%(S D=17.5)$ and $80.0 \%(S D=20.1)$ of the intervals during the 15 - and 30 -day follow-up phases, respectively.

In addition to increased academic engagement by all participants, two interesting trends emerged. First, participants assigned to a treatment strategy that was primarily antecedent-based displayed higher rates of academic engagement then those assigned to a treatment strategy that was primarily consequentbased, regardless of function of behavior. Participants receiving a primarily antecedent-based treatment strategy displayed academic engagement an average of $91.6 \%(S D=9.3)$ and $86.7 \%(S D=19.9)$ of the intervals during Treatment phases 1 and 2, respectively, whereas, participants receiving a primarily consequent-based treatment strategy displayed academic engagement an average of $82.5 \%(S D=13.3)$ and $79.6 \%$ ( $S D=16.9)$ of the intervals during the two treatment phases. Second, participants whose disruptive behavior was functionally related to task-avoidance displayed substantially higher levels of academic engagement when assigned to an antecedent-based treatment strategy, than when assigned to a consequent-based treatment strategy. Participants assigned to an antecedent-based treatment strategy whose disruptive behavior was functionally related to task-avoidance displayed academic engagement an average of $96.9 \%(S D=4.3)$ and $96.0 \%(S D=3.5)$ during Treatment phases 1 and 2 respectively, whereas, participants assigned to a consequent-based treatment strategy whose behavior was functionally related to task-avoidance displayed academic engagement an average of $75.9 \%(S D=13.3)$ and $68.9 \%(S D=16.4)$ during the two treatment phases. Although statistical analyses were not conducted, visual inspection of the mean percentages of academic engagement (and disruptive behavior) clearly 
demonstrate that antecedent-based treatment strategies were substantially more effective for participants whose behavior was functionally related to task-avoidance.

When conducting a similar study with second grade students, Restori et al. (in review) found that antecedent-based treatment strategies were significantly more effective with students whose disruptive behavior was functionally related to attention seeking. These results indicate that treatment strategies that are primarily antecedent-based may be more effective for older children whose disruptive behavior is functionally related to task-avoidance, whereas, antecedent-based treatment approaches may be more effective for younger children whose disruptive behavior is functionally related to attention-seeking.

\section{Disruptive behavior}

Most participants displayed stable patterns of disruptive behavior during the initial baseline sessions. All participants met the pre-established criteria regarding disruptive behavior for inclusion into the study. Overall, participants displayed disruptive behavior an average of $59.5 \%(S D=20.4)$ of the intervals during the initial baseline phase and $38.3 \%(S D=23.0)$ during the reversal to baseline phase. Commensurate to the previously reported increases in academic engagement, all participants showed a significant decrease in disruptive behavior during both treatment phases. Overall, the mean of disruptive behavior decreased to $6.8 \%(S D=7.6)$ of the intervals during Treatment phase 1 and $6.5 \%(S D=8.0)$ during Treatment phase 2. Overall disruptive behavior decreased to an average of $15.6 \%(S D=23.0)$ and $10.8 \%(\mathrm{SD}=16.0)$ of the intervals during the 15- and 30-day follow-up phases, respectively.

Similar to academic engagement, all participants demonstrated a significant reduction in disruptive behavior. In addition, the two previously described trends pertaining to academic engagement were commensurately observed with disruptive behavior. First, participants assigned to a primarily antecedent-based treatment strategy displayed lower levels of disruptive behavior then those assigned to a treatment strategy that was primarily consequent-based regardless of function of behavior. Participants receiving an antecedent-based treatment strategy displayed disruptive behavior an average of $4.3 \%$ $(S D=6.0)$ and $5.4 \%(S D=9.9)$ of the intervals during Treatment phases 1 and 2, respectively, whereas, participants receiving a consequent-based treatment strategy displayed disruptive behavior an average of $9.1 \%(S D=8.4)$ and $7.5 \%(\mathrm{~S} D=5.8)$ of the intervals during the two treatment phases. Second, participants whose disruptive behavior was functionally related to task-avoidance displayed lower levels of disruptive behavior when assigned to a primarily antecedent-based treatment strategy, than when assigned to a primarily consequent-based treatment strategy. Participants assigned to an antecedent-based treatment strategy whose disruptive behavior was functionally related to task-avoidance displayed disruptive behavior an average of $0.89 \%(S D=2.3)$ and $0.85 \%(S D=1.2)$ during Treatment phases 1 and 2 respectively, whereas, participants assigned to a consequent-based treatment strategy whose behavior was functionally related to task-avoidance displayed disruptive behavior an average of $13.1 \%(S D=9.7)$ and $9.0 \%(S D=4.6)$ during both treatment phases.

\section{DISCUSSION}

The current study had two primary objectives. First, was to explore the practicality of conducting functional assessments within general education settings with typically developing children who displayed excessive rates of disruptive behavior and poor academic engagement as a function of either attention seeking or task avoidance. If it can be demonstrated that functional assessments can be conducted effectively and with minimal intrusion within a general education classroom setting, school psychologists and teachers would be better able to meet the growing demand of students experiencing disruptive patterns 
of behavior. Second, was to compare treatment strategies that were primarily antecedent-based with treatment strategies that were primarily consequent-based. Since teachers often use consequent-based treatment strategies for addressing the needs of children exhibiting behavioral difficulties, determining the effectiveness and efficiency of antecedent-based treatment strategies would likely have practical implications for teachers working with children demonstrating excessive patterns of disruptive behavior within a general education classroom setting.

Regarding the first objective, teachers and a school psychologist participated in a collaborative approach in conducting an FBA and developing and implementing a behavior plan for each of the participants. The school psychologist was primarily responsible for gathering data that would be used to generate a hypothesis statement regarding the function of behavior. As previously stated, this was accomplished via systematic student observations, teacher interviews, and the SSRS-T. The school psychologist and teacher then: (a) analyzed the data, (b) reviewed information obtained from the teacher interview and $S S R S-T$, (c) generated a hypothesis statement regarding the function of behavior, and (d) developed a behavior plan. Once the behavior plan was developed, teachers and participants were trained in intervention procedures. The teachers were primarily responsible for implementing the behavior plans and completing component analysis checklists. The school psychologist was primarily responsible for gathering student outcome and treatment integrity data. Results of this consultation-based, collaborative approach for conducting FBAs within a general education classroom was successful in identifying the variables maintaining disruptive behavior for students whose behavior was functionally related to either task-avoidance or attention-seeking.

Regarding the second objective, treatment strategies that were primarily antecedent-based were more effective than treatment strategies that were primarily consequent-based for reducing disruptive behavior and increasing academic engagement for all participants. Closer inspection of the data indicate that antecedent-based treatment strategies were particularly more effective than consequent-based treatment strategies for reducing disruptive behavior and increasing academic engagement when disruptive behavior was functionally related to task avoidance. These results are of particular interest when compared to a similar study conducted by Restori and colleagues (in review) with second grade students, wherein antecedent-based treatment strategies were particularly more effective for students whose disruptive behavior was found to be functionally related to attention seeking. Although the conclusions that can be drawn from these two studies are speculative due to the small sample size of each, the age differences of the participants in each study may provide the most plausible explanation for the differences found. That is, an antecedent-based treatment strategy such as self-monitoring may have been more effective with the younger, second grade students whose disruptive behavior was functionally related to attention seeking because self-monitoring provided them with sufficient attention from their teacher's resulting in the observed increase in academic engagement and reduction in disruptive behavior. Whereas, an antecedent-based intervention such as task-modification may have been more successful with fifth grade students whose disruptive behavior was functionally related to task avoidance where the academic demands were more rigorous because it provided the necessary support, which subsequently produced the observed reduction in disruptive behavior and increase in academic engagement. Results of both studies indicate that treatment strategies that were primarily antecedent-based were more effective than consequent-based treatment strategies for second and fifth grade students whose disruptive behavior was related to either task-avoidance or attention-seeking. Anecdotally, teachers reported that interventions that were primarily antecedent-based were easier to implement and monitor, that consequent-based treatment strategies were exhausting, and that students were eager to participate in antecedent-based 
treatment strategies such as self-monitoring and task-modification. This would indicate that antecedentbased treatment strategies were not only as effective as consequent-based treatment strategies, but less labor intensive and efficient.

\section{Limitations of the Current Study}

The current study has several important limitations that must be noted. First, due to the small sample of participants used in this study, results regarding external validity should be interpreted cautiously. The issue of external validity was partially addressed by employing two participants (replication) for each of the four possible functions of behavior and intervention strategy combinations. Second, all of the participants in the study were male, therefore, results of treatment outcomes must also be interpreted cautiously regarding their application to females. Although the extent to which these results may apply to females is a limitation of the study, it is important to note that boys are more likely to engage in externalizing behaviors (i.e., disruptive behavior) at a rate of approximately 4:1 (Walker et al., 2004). Third, statements regarding the generalizability of the participants' behavior are limited, since participants were observed once per day for one 15-minute session and only during a reading or reading related lesson. Although the daily 15-minute observations provide a "snapshot" of behavior, the generalization of behavior across settings (e.g., classrooms, playground, home), lessons (e.g., math, social studies), and situations (e.g., transitions, independent seatwork, lessons) cannot be assumed. Fourth, functional analyses were not conducted therefore, the hypothesized function of disruptive behavior was not experimentally validated. Although functional assessments yield convergent sources of information regarding the function of behavior, a functional analysis is needed to validate the hypothesis regarding function of behavior. Although functional analyses were not conducted and the function of behavior was not validated, use of an ABAB single-case design and the success of the interventions for all participants indicate that the correct function of behavior was identified. Fifth, results regarding function of behavior should be interpreted cautiously since the participants demonstrated disruptive behavior that was functionally related to either task-avoidance or attention-seeking. It is very likely that some students will engage in disruptive behavior that serves a dual function, is undifferentiated, or is functionally related to some other variable (e.g., sensory reinforcement). Sixth, the distinction between teacher and peer attention was not made. It is probable that students from different age groups will be differentially affected by either teacher and/or peer attention. Seventh, comparing intervention strategies that are primarily antecedent- or consequentbased may reveal which intervention strategies are better, that is, are more effective and/or easier for teachers to implement, however, such a comparison may not demonstrate which approach is best.

\section{Implications for Research and Practice}

Results and limitations of the current study indicate that a number of issues will need to be addressed through future research. First, the use of functional assessments in applied settings such as special and general education classrooms with typically developing children and children either at-risk or identified as EBD is of utmost importance. Sasso and his colleagues (2001) raised a number of important issues regarding functional assessment/analysis research that has been conducted in applied settings. Some of these concerns include the use of functional analysis within applied settings, validating the procedures and techniques used when conducting functional assessment research in applied settings, and developing a clear methodology for how each of these techniques and procedures contribute to the development of a hypothesis regarding function of behavior. Each of these concerns must be addressed if a clear, empirically validated science for using applied behavior analysis methodology within applied settings is to 
grow.

Second, the field of applied behavior analysis has set a "high bar" regarding how behavior assessment and interventions should be researched and applied. In the context of university research settings where personnel and resources may be more readily available, such standards may be justifiable, attainable, and practical, however, within public school classroom settings, such standards may not be reasonable. Therefore, those who conduct research in applied behavior analysis and those who apply it in "real world" settings will need to find a common ground from which to build a research base and practice. Johnston, Foxx, Jacobson, Green, and Mulick (2006) have identified two "movements" that have had a significant impact within the behaviorist field. One movement consists of the applied behavior analysts (ABA) who adhere to stringent experimental rigor, high standards with regard to internal validity, and has a well-documented research base. The second and newer movement is comprised of the positive behavior support (PBS) researchers and practitioners that apply variations of applied behavior analysis, usually within school settings. PBS researchers and practitioners are willing to relinquish some of the high research standards set forth by ABA in the interest of using the behavioral technology with children in school settings. Scott and his colleagues (2004) maintain that it is unrealistic to expect practitioners working within public school settings to adhere to the rigorous experimental standards set forth by ABA. Thus, those who research functional assessment in applied settings must continue to build a research base to establish a minimum standard for conducting functional assessment research in applied settings and its use in practice.

Third, future research using functional assessment procedures in applied settings should consider developing assessment procedures that may be employed across a variety of settings, lessons, and situations to further establish their external validity and generalizability. Functional assessment procedures should be modified to be less intrusive and restrictive to ensure success within applied settings. For example, classroom teachers may find a functional assessment observation form to be more practical than a partial-interval, time-sampling procedure for gathering information and data pertaining to the function of behavior. Functional assessment observation forms yield important information regarding the description, frequency, duration, time, and hypothesized function of maladaptive behavior.

Fourth, develop treatment plans that utilize antecedent- and/or consequent-based treatment strategies across a variety of settings, lessons, and situations to further establish their external validity and generalizability. Treatment packages should be modified to be less intrusive and restrictive to ensure success within special and general education classrooms. Treatment strategies such as self-monitoring can be modified to be practical for use within classroom settings. For example, the current study modified the self-monitoring procedure described by Shapiro and Cole (1992) to fit the general education curriculum. The previously described observation and self-monitoring procedures can be modified and used across a variety of settings, lessons, and situations within general education settings.

Fifth, future research should classify students whose disruptive behavior is functionally related to attention-seeking, as seeking either teacher or peer attention. The current study did not make the distinction between peer and teacher attention, however, it is likely that some students prefer peer attention, others prefer teacher attention, and others are reinforced by both teacher and peer attention. Consideration of the type of attention-seeking (i.e., peer or teacher attention) among students from different age groups is likely to have a substantial impact on the selection of both assessment and treatment procedures.

Sixth, future research focusing on treatment strategies that are primarily antecedent-based should focus on the following four aspects: (a) modifying established antecedent-based treatment strategies such as self-monitoring and task-modification for use within general education settings, (b) developing 
new and reliable antecedent-based treatment strategies to prevent the occurrence of problem behaviors within general education settings, (c) providing social validation for the use of antecedent-based treatment strategies within general education settings, and (d) dissemination of antecedent-based treatment strategies to classroom teachers in order to expand their repertoire for implementing effective classroom management. As previously stated, antecedent-based treatment strategies should be part of a comprehensive approach for meeting the challenges posed by students with behavioral disorders.

\section{Conclusion}

This investigation provided evidence that functional assessments can be used within a general education classroom with typically developing students that demonstrate behavior problems. Results of the study indicate that all participants demonstrated decreased disruptive behavior and increased academic engagement. Results of the current study also indicated that antecedent-based treatment strategies were more effective than the more typically used consequent-based treatment strategies. Finally, results of the study indicate that school psychologists and teachers may be able meet the academic and behavioral needs of students in general education classrooms using a collaborative approach.

\section{REFERENCES}

Becker, W., Madsen, C., Arnold, C., \& Thomas, D. (1967). The contingent use of teacher attention and praise in reducing classroom behavior problems. The Journal of Special Education, 1, 55-67.

Clarke, S., Dunlap, G., Foster-Johnson, L., Wilson, D., White, R., \& Vera, A. (1995). Improving the conduct of students with behavioral disorders by incorporating student interests into curricular activities. Behavioral Disorders, 20, 221-237.

Cooper, J. O., Heron, T. E., \& Heward, W. L. (2007). Applied Behavior Analysis (2 ${ }^{\text {nd }}$ ed.). Upper Saddle River, NJ: Pearson Prentice Hall.

Dunlap, G., \& Kern, L. (1996). Modifying instructional activities to promote desirable behavior: A conceptual and practical framework. School Psychology Quarterly, 11, 297-312.

Dunlap, G., Kern, L., dePerczel, M., Clarke, S., Wilson, D., Childs, K. E., White, R., \& Falk, G. D. (1993). Functional analysis of classroom variables for students with emotional and behavioral disorders. Behavioral Disorders, 18, 275-291.

Dunlap, G., White, R., Vera, A., Wilson, D., \& Panacek, L. (1996). The effects of multi-component, assessmentbased curricular modifications of the classroom behavior of children with emotional and behavioral disorders. Journal of Behavior Education, 6, 481-500.

Fuchs, D. \& Fuchs, L. (1989). Exploring effective and efficient prereferral interventions: A component analysis of behavioral consultation. School Psychology Review, 18, 260-283.

Gresham, F. M. (1989). Assessment of treatment integrity in school consultation and prereferral intervention. School Psychology Review, 18, 37-50.

Gresham, F. M., \& Elliott, S. N. (1990). Social Skills Rating System. Circle Pines, MN: American Guidance Service.

Gresham, F. M., Watson, T. S., \& Skinner, C. (2001). Functional behavior assessment: Principles, procedures, and future directions. School Psychology Review, 30, 156-172.

Horner, R. D. (1994). Functional assessment contributions and future directions. Journal of Applied Behavior Analysis, 27, 401-404.

Horner, R. H., \& Sugai, G. (2000). School-wide behavior support: An emerging initiative (special issue). Journal of Positive Behavioral Interventions, 2, 231-232.

Iwata, B. A., Dorsey, M. F., Slifer, K. J., Bauman, K. E., \& Richmond, G. S. (1982). Toward a functional analysis of self-injury. Analysis and Intervention in Development Disabilities, 2, 1-20.

Johnston, J. M., Foxx, R. M., Jacobson, J. W., Green, G., \& Mulick, J. A. (2006). Positive behavior support and applied behavior analysis. The Behavior Analyst, 29, 51-74.

Johnston, J. M., \& Pennypacker, H. S. (1993). Strategies and tactics of behavioral research (2 ${ }^{\text {nd }}$ ed.). Hillsdale, NJ: Lawrence Erlbaum. 
Kamps, D., Wendland, M., \& Culpepper, M. (2006). Active teacher participation in functional behavior assessment for students with emotional and behavioral disorders risks in general education classrooms. Behavioral Disorders, 31, 128-146.

Kern, L., \& Clemens, N. H. (2007). Antecedent strategies to promote appropriate classroom behavior. Psychology in the Schools, 44, 65-75.

Kern, L., Delaney, B., Clarke, S., Dunlap, G., \& Childs, K. E. (2001). Improving the classroom behavior of students with emotional and behavioral disorders using individualized curricular modifications. Journal of Emotional and Behavioral Disorders, 9, 239-247.

Kern, L., Hilt, A. M., \& Gresham, F. M. (2004). An evaluation of the functional behavior assessment process used with students with or at risk for emotional and behavioral disorders. Education and Treatment of Children, 27, 440-452.

Lane, K. L., Robertson, E. J., \& Graham-Bailey, M. A. L. (2006). An examination of school-wide interventions with primary level efforts conducted in secondary schools: Methodological considerations. In T. E. Scruggs \& M. A. Mastropieri (Eds.), Applications of research methodology: Advances in learning and behavioral disabilities (vol. 19). Oxford, UK: Elsevier.

Lane, K. L., Umbreit, J., \& Beebe-Frankenberger, M. (1999). A review of functional assessment research with students with or at-risk for emotional and behavioral disorders. Journal of Positive Behavioral Interventions, 1 , 101-111.

Lane, K. L., Weisenbach, J. L., Little, M. A., Phillips, A., \& Wehby, J. (2006). Illustrations of function-based interventions implemented by general education teachers: Building capacity at the school site. Education and Treatment of Children, 29, 549-671.

Lennox, D. B., Miltenberger, R. G., Spengler, P., \& Erfanian, N. (1988). Decelerative treatment practices with persons who have mental retardation: A review of five years of literature. American Journal of Mental Retardation, 92, 492-501.

Lewis, C., \& Sugai, G. (1996). Functional assessment of problem behavior: A pilot investigation of the comparative and interactive effects of teacher and peer social attention on students in general education settings. School Psychology Quarterly, 11, 1-19.

Marcus, B. A., \& Vollmer, T. R. (1996). Combining non-contingent reinforcement and differential reinforcement schedules as treatment for aberrant behavior. Journal of Applied Behavior Analysis, 29, 43-51.

Martens, B. K., Peterson, R. 1., Witt, J. C., \& Cirone, S. (1986). Teacher perceptions of school-based interventions. Exceptional Children, 53, 213-223.

Newcomer, L. L., \& Lewis, T. J. (2004). Functional behavior assessment: An investigation of behavior reliability and effectiveness of function-based interventions. Journal of Emotional and Behavioral Disorders, 12, $168-181$.

Olweus, D. (1979). Stability of aggressive reaction patterns in males: A review. Psychological Bulletin, 86, 852875.

Restori, A. F., Gresham, F. M., Chang, T., Lee, H. B., Laija-Rodriquez, W. (2007). Functional assessment-based interventions: Outcomes of antecedent- and consequent-based tactics in general education classrooms. Manuscript submitted for publication.

Sasso, G. M., Conroy, M. A., Stichter, J., \& Fox, J. J. (2001). Slowing down the bandwagon: The misapplication of functional assessment for students with emotional and behavioral disorders. Behavioral Disorders, 26, 282296.

Scott, T. M., Bucalos, A., Liaupsin, C., Nelson, C. M., Jolivette, K., \& DeShea, L. (2004). Using functional behavior assessment in general education settings: Making a case for effectiveness and efficiency. Behavioral Disorders, 29, 189-201.

Shapiro, E. S., \& Cole, C. L. (1992). Self-monitoring. In T. H. Ollendick \& M. Hersen (Eds.). Handbook of child and adolescent assessment ( $2^{\text {nd }}$ ed). pp. 124-139). New York: Pergmon.

Umbreit, J. (1996). Functional analysis of disruptive behavior in an inclusive classroom. Journal of Early Intervention, 20, 18-29.

Umbreit, J., \& Blair, K. S. (1997). Using structural analysis to facilitate treatment of aggression and noncompliance in a young child at-risk for behavioral disorders. Behavioral Disorders, 22, 75-86.

Umbreit, J., Lane, K. L., \& Dejud, C. (2004). Improving classroom behavior by modifying task difficulty: Effects of increasing the difficulty of too-easy tasks. Journal of Positive Behavior Interventions, 6, 13-20.

Walker, H. M., Ramsey, E., \& Gresham, F. M. (2004). Antisocial behavior in school: Evidenced-based practices (2 ${ }^{\text {nd }}$ ed.). Belmont, CA: Wadsworth/Thomson Learning.

Walker, H. M., \& Severson, H. H. (1991). Systematic Screening for Behavior Disorders (SSBD): User's guide and technical manual. Longmont, CO: Sopris West. 